Article

\title{
Numerical Treatments of Slipping/No-Slip Zones in Cold Rolling of Thin Sheets with Heavy Roll Deformation
}

\author{
Yukio Shigaki ${ }^{1, \dagger}$, Rebecca Nakhoul ${ }^{2, \dagger}$ and Pierre Montmitonnet ${ }^{2, \dagger, *}$
}

1 Federal Centre of Technological Education of Minas Gerais (CEFET-MG), Belo

Horizonte Unit - Campus II, Amazonas Avenue, 7675-CEP 30510-000-Belo Horizonte/MG, Brazil; E-Mail: yukio@des.cefetmg.br

2 Centre de Mise en Forme des Matériaux (CEMEF), MINES ParisTech, PSL Research University, CNRS UMR 7635, CS 10207 Rue Claude Daunesse, Sophia Antipolis Cedex, 06904, France;

E-Mail: rebecca.nakhoul@mines-paristech.fr

$\dagger$ These authors contributed equally to this work.

* Author to whom correspondence should be addressed;

E-Mail: pierre.montmitonnet@mines-paristech.fr;

Tel.: +33-04-9395-7414; Fax: +33-04-9238-9752.

Academic Editor: Jeffrey L. Streator

Received: 22 December 2014 / Accepted: 6 March 2015 / Published: 2 April 2015

\begin{abstract}
In the thin sheet cold rolling manufacturing process, a major issue is roll elastic deformation and its impact on roll load, torque and contact stresses. As in many systems implying mechanical contact under high loading, a central part is under "sticking friction" (no slip) while both extremities do slip to accommodate the material acceleration of the rolled metal sheet. This is a crucial point for modeling of such rolling processes and the numerical treatment of contact and friction ("regularized" or not), of the transition between these zones, does have an impact on the results. Two ways to deal with it are compared (regularization of the stick/slip transition, direct imposition of a no-slip condition) and recommendations are given.
\end{abstract}

Keywords: strip rolling; modeling; Finite Element Method; Slab method; slip; friction; regularization 


\section{Introduction on Strip Rolling Models, Roll Deformation and the Role of the Friction Stress}

Rolling is one of the most important metal manufacturing processes. Starting from continuously cast slabs, steel is first hot rolled then cold rolled. This latter stage is the one of interest in this paper. As the material is hard and thin, large contact pressures result in significant roll deformation, which has a major impact on the process control and on strip geometry [1]. The most impacted characteristics are thickness profile and flatness defects (see Figure 1) in the case of thin cold rolled flat products, named strips between 0.1 and $1 \mathrm{~mm}$ thick, and foils below $100 \mu \mathrm{m}$. In the present paper, where the focus is on friction models and their consequences, it is sufficient to work with 2D models in a longitudinal cross section, where strains and stresses are assumed constant along the width direction. In this plane, the elastic roll deformation problem is called roll flattening.

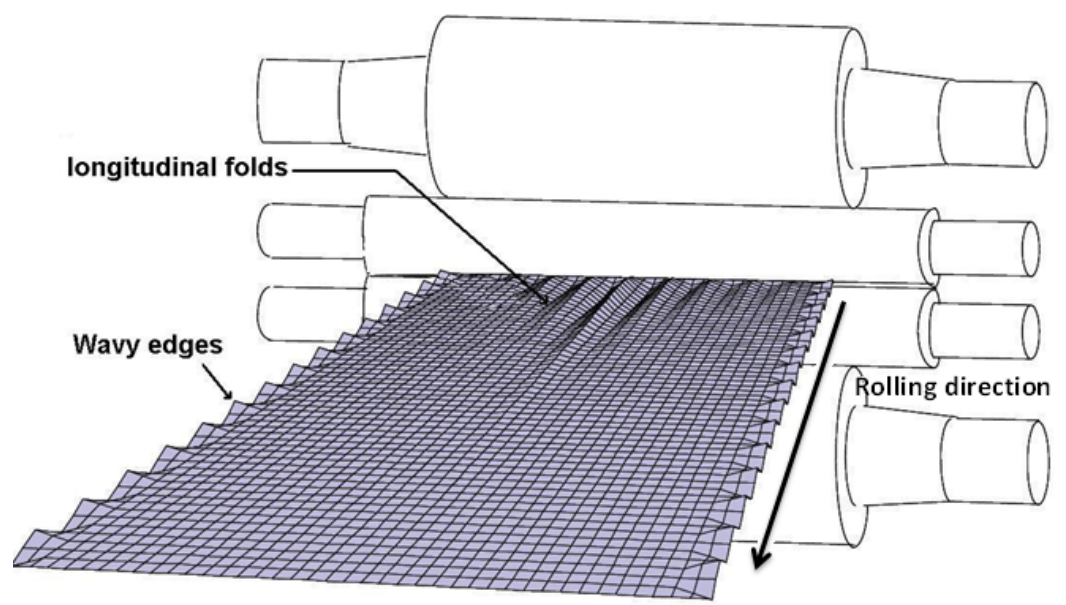

Figure 1. Schematic representation of the rolling process, showing the roll stack (work roll (WR), back-up roll (BUR)) and thin strip with typical flatness defects.

\subsection{Elastic Roll Deformation Modeling}

It is important to realize that a concentrated line loading on a cylinder results in a singular solution [2]. As a rolling mill roll is highly loaded on a very small part of its periphery, the problem is not singular but very stiff; however, simple as it may look, it remains an open one.

First estimations of roll deformation were based on the assumption of a quasi-Hertzian contact stress field (elliptical profile), from which Hitchcock's formula [3] was derived. It allowed calculating an equivalent, increased roll radius, which was then used in most of the early rolling models, such as the Bland and Ford model [4]. Roll deformation was coupled to strip deformation in an iterative way: plastic or elastic-plastic strip deformation analysis gives a stress profile, which is applied on the roll to give the deformed roll radius, which is used in next iteration of strip model, etc.

The limitation of Hitchcock's formula for highly loaded contacts such as found with hard, thin strip was soon recognized: for large roll deformation, the iterative process described above fails to converge. Roll radius is increased by the roll load; this makes the contact length longer, which makes the load grow, which increases the roll radius in an endless process. It has been estimated that whenever the calculated deformed roll radius reaches the double of the initial one, the results are suspect and for still 
higher ratios, divergence may occur [5]. Therefore, much more precise methods were developed to show that indeed non-circular arc roll deformation models were necessary:

- First the Influence Function Method initiated by Jortner et al. [6] and its numerous variants, still in use today.

- Then the Finite Element Method (FEM) introduced by Atreya and Lenard [7] and Montmitonnet et al. [5], which is now practically abandoned in 2D models due to its much higher cost. It subsists in 3D rolling models [8] as an alternative to the IFM, which becomes quite complex in this case.

\subsection{Plastic Strip Deformation Modeling and Coupling with Roll Deformation}

As for the strip, its elastic-plastic deformation 2D analysis is most of the time based on the Slab Method (SM). It assumes (i) no dependence of stress and strain on the thickness coordinate either and (ii) the (Oxyz) frame is the principal frame everywhere, i.e., no shear strains and stresses need to be considered. The latter assumption is sometimes relieved using Orowan's model to include an approximation of shear effects [9]. In 3D, the FEM is used most of the time as the SM is difficult to extend rigorously in this case.

The roll/strip model coupling technique is essential. The iterative process described above often fails to converge if no precautions are taken. This is why alternatives have been proposed, based on conjugate gradient [10] or one-domain FEM computation with internal discontinuity - the roll-strip interface [11]. However the fixed point iterative technique remains the only one in use. The solution to convergence problems in severe cases relies on relaxation: only a small fraction of the roll surface displacement calculated at current iteration is used to increment roll shape for next iteration. Recent models propose adaptive management of the relaxation coefficient, as a function of the convergence performance during the last few iterations $[12,13]$.

Difficult convergence is related to the normal stress peak found near the "neutral point" where sliding direction reverses. Indeed, due to incompressibility conjugated with the necessary material acceleration as the thickness reduction proceeds, the relative velocity is negative on the entry side and positive on the exit side. This peak can be so sharp as to promote a "trough" in the elastically deformed roll profile, i.e., the gap (=the strip thickness) locally re-increases in the central part. This phenomenon, of the order of a micrometer or less, is now thought to be real [14]. It makes the convergence particularly difficult as the strip may fall back temporarily in the elastic unloading regime. This is why Matsumoto [12], following Fleck and Johnson [15], sets a limit to the shape, assuming that the roll gap is at most parallel in the central part: $\mathrm{d} t / \mathrm{d} x=0 ; \mathrm{d} t / \mathrm{d} x>0$ is forbidden before contact exit ( $t$ is the strip thickness, $x$ the abscissa).

\subsection{The role of Friction: Regularization}

Such a sharp peak of normal stress is strongly dependent on the friction stress in the neighborhood. In fact, it is easy to show through the equilibrium equations that when rolling thin strips, the major part of the stress is due to friction:

$$
\frac{\partial \sigma_{y y}}{\partial x} \sim \frac{\partial \sigma_{x x}}{\partial x}=-\frac{\partial \sigma_{x y}}{\partial y}
$$


$\sigma$ is the Cauchy stress tensor, $x$ being the rolling direction and $y$ the normal direction. Figure 2 illustrates the impact of friction on the normal and tangential stress profiles, on the roll-deformed shape and on the sliding velocity profile. A very thin steel strip is taken as an example, $0.3 \mathrm{~mm}$ reduced to $0.21 \mathrm{~mm}$ using $600 \mathrm{~mm}$ diameter rolls. When friction increases from $\mu=0.02$ to $\mu=0.035$, the roll load, which is the integral of the normal stress profile, is multiplied by ca. 3.5 and a central flat, no-slip region appears.
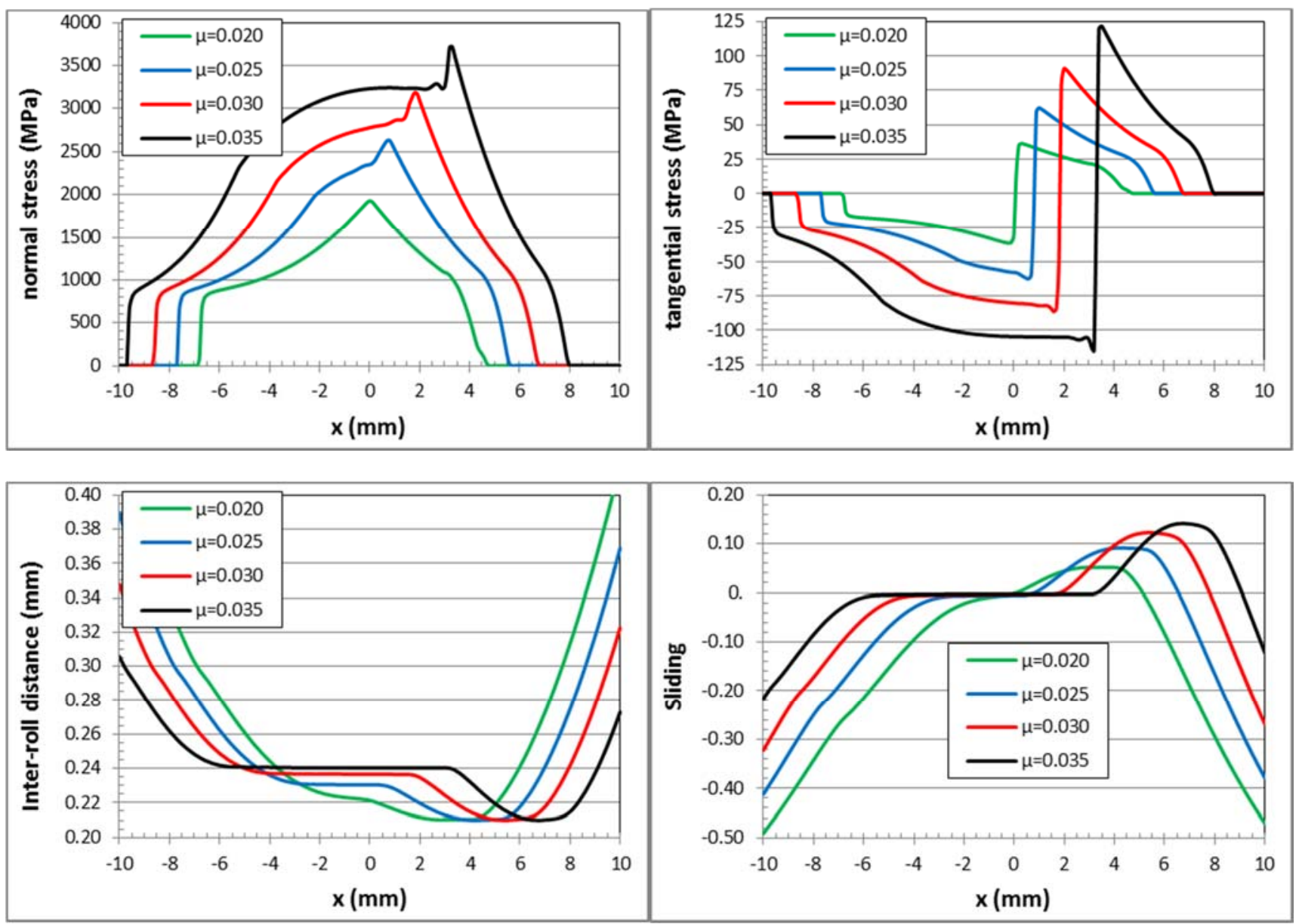

Figure 2. Impact of Coulomb friction coefficient $\mu$ on mechanical variables in thin strip cold rolling. From left to right and top to bottom, profiles of the normal stress, the friction stress, the deformed roll and the sliding velocity (compare with similar figures in [15]).

The way the friction stress model is implemented is therefore critical to the precision of the rolling model. A correct friction model must include a threshold, a stick-slip transition in the form:

$$
\begin{aligned}
& |q|=q_{\mathrm{c}} \text { if } v_{\mathrm{s}} \neq 0 \text { (slip) } \\
& |q| \leq q_{\mathrm{c}} \text { if } v_{\mathrm{s}}=0 \text { (stick) }
\end{aligned}
$$

$(p, q)$ are, respectively, the normal and friction stress, $v_{\mathrm{s}}$ is the sliding velocity, $q_{\mathrm{c}}$ a threshold stress for sliding, to be specified by a friction law. Though the friction factor model is certainly preferable under high pressures as found in thin strip rolling, most authors use Coulomb friction i.e., $q_{\mathrm{c}}=\mu \cdot p$ :

$$
\begin{aligned}
& |q|=\mu \cdot p \text { if } v_{\mathrm{s}} \neq 0 \text { (slip) } \\
& |q| \leq \mu \cdot p \text { if } v_{\mathrm{s}}=0 \text { (stick) }
\end{aligned}
$$


The stick condition $|q|<\mu p$ results in a decrease of the friction stress, therefore a decrease of the normal stress according to Equation (1). This condition can be met in very highly loaded cases in the central part where pressure is so high as to block sliding. The corresponding reduction of hydrostatic pressure blunts the normal stress peak and reduces the local roll deformation. As a consequence, convergence is made easier - by a real, physical effect. However, some models impose sliding to avoid dealing with the complexity of the stick-slip transition. Such models may have a convergence problem. Some solve it by introducing a regularization of friction, to decrease it artificially in the critical area around the neutral point. It consists in smoothing the stick-slip "step" function by multiplying $q_{\mathrm{c}}$ by a continuous and differentiable function e.g., [11]:

$$
|q|=\mu p \cdot \frac{v_{\mathrm{s}}}{\sqrt{v_{\mathrm{s}}^{2}+K^{2}}}
$$

$K$ is the regularization factor. Its choice (with respect to the expected values of the sliding velocity) is essential to regularize the mathematical treatment without transforming too much the physical problem. This trick is most useful in the FEM where the derivative of friction with respect to sliding velocity or displacement is needed to build the stiffness matrix. This derivative is infinite at stick/slip transition $v_{\mathrm{s}}=$ 0 if the step function is kept. But regularization of friction is also used in the SM context.

Note that Sutcliffe and Montmitonnet [16] use a second type of friction regularization for the extreme case of $\mathrm{Al}$ thin foil rolling, using a slope-dependent $(\mathrm{d} y / \mathrm{d} x)$ term.

\subsection{Purpose and Organization of the Paper}

The main intention of this paper is to draw attention to the capabilities and risks of the friction regularization technique, by quantifying the impact this "numerical trick" may have on the stresses, on roll deformation and on rolling load. Comparison with a non-regularized formulation with an adequate treatment of the stick-slip transition will lead to recommendation on the choice of $K$. It must be emphasized that these effects are maximized here by selecting thin, hard strip rolling as the test case - but this is where regularization is useful indeed. Two mathematical formulations of the strip rolling process will be addressed, the Slab Method (SM) and a Finite Element Model (FEM). The goal is not to describe them in details or to compare them either; this has been done a number of times in the past. The test cases are such that we do not expect much difference between them anyway. The purpose is to show that the behavior of the friction regularization technique is independent of the type of model, provided it is implemented correctly.

First, the models are described in Section 2, starting with the Slab Method (SM) then the Finite Element Model (FEM). In Section 3, the impact of regularization on contact stresses, relative velocity and roll deformation are presented and shown important in thin strip rolling whatever the mathematical formulation of the problem. Section 4 discusses the choice of the regularization factor, and the extension of its formulation to investigate friction laws with different static $v s$. dynamic friction coefficients. 


\section{Models Description}

\subsection{Slab Method-Based Model}

\subsubsection{Stress Field in the Strip}

The formulation presented next is taken mainly from the work by Le and Sutcliffe [17]. The constitutive model is elastic-plastic work-hardening. According to the standard Slab Method, it is assumed that strain and stresses do not vary in the thickness direction, i.e., are independent of $y$. The equilibrium of forces applied to the slab (Figure 3) in the rolling direction writes:

$$
t \frac{\mathrm{d} \sigma}{\mathrm{d} x}+(\sigma+p) \frac{d t}{d x}+2 q=0
$$

where $x$ is the coordinate in the rolling direction, $t$ is the strip thickness, $\sigma$ is the tensile stress in the rolling direction, $p$ is the interface pressure and $q$ is the shear stress.

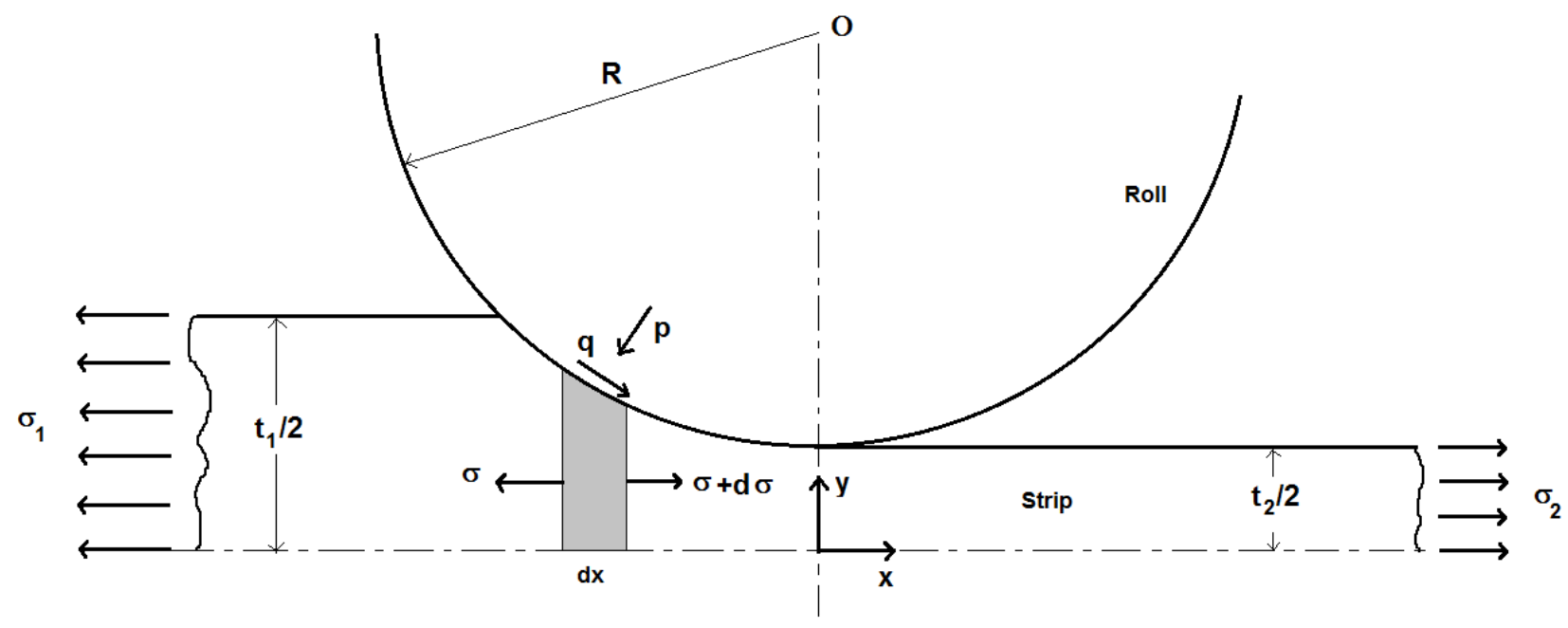

Figure 3. Symbols used in the equations of slab method.

Deformation starts with an elastic compression at onset of contact. Stresses grow and, when the yield condition is met, plastic deformation occurs, under slip condition as the strip speed increases. As in Le and Sutcliffe [17], a central flat, sticking zone may occur under higher loads; conditions for this are described below. In this case, a second plastic reduction zone with slip will follow. In all cases, a final elastic unloading zone bounds the contact, starting at the point of minimum thickness $x_{\mathrm{d}}$ (Figure 4). 


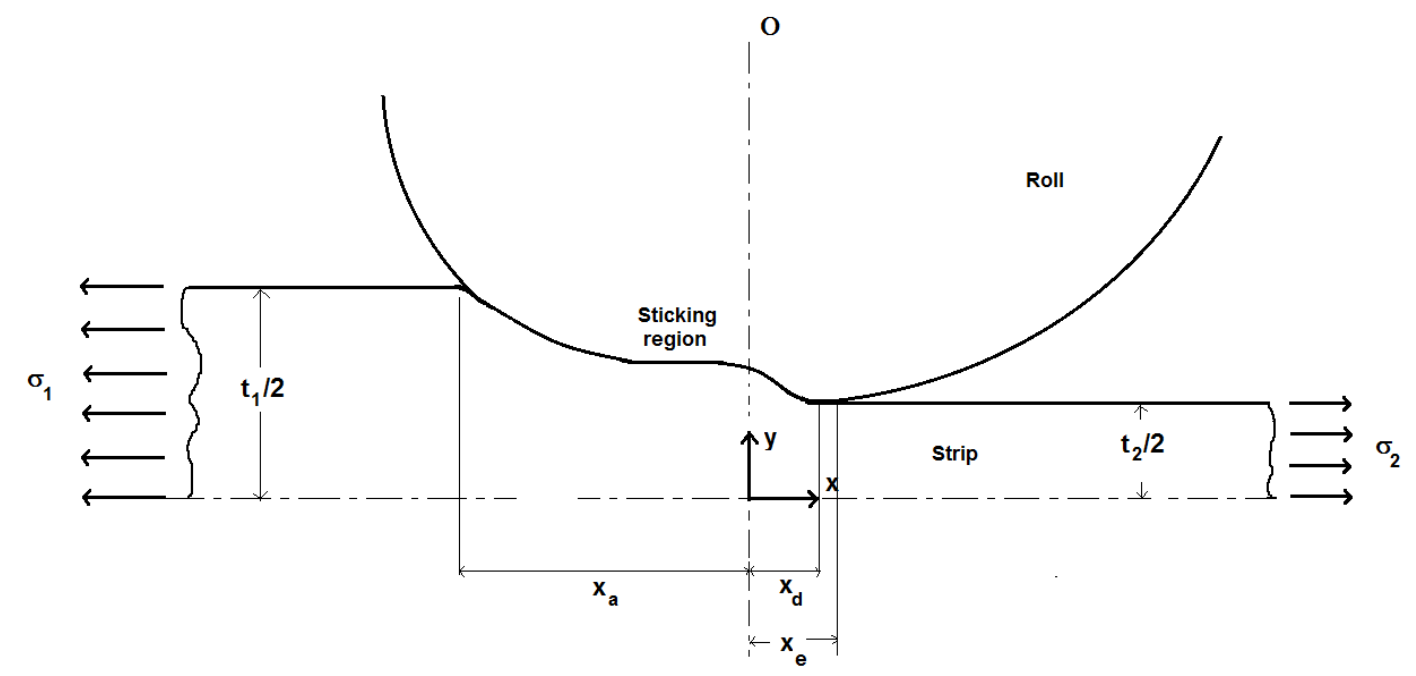

Figure 4. Deformed arc and sticking region ((CPZ) Contained Plastic Zone).

The equations governing the different zones are given hereafter.

(a) In the plastic slip region, the equilibrium Equation (5) is solved together with the elastic-plastic constitutive model. A Tresca yield criterion is assumed: $p+\sigma=Y_{\mathrm{s}}\left(Y_{\mathrm{s}}\right.$ is the plane strain yield stress of the strip), giving, once reported into Equation (5):

$$
\frac{\mathrm{d} p}{\mathrm{~d} x}=\frac{Y_{\mathrm{s}}}{t} \frac{\mathrm{d} t}{\mathrm{~d} x}+\frac{2 q}{t}+\frac{\mathrm{d} Y_{\mathrm{s}}}{\mathrm{d} x}
$$

Assuming a constant Coulomb friction coefficient $\mu$, friction stress $q$, wherever sliding is present, is given by:

$$
q= \pm \mu p
$$

where the positive sign is used for the backward slip at entry and the negative sign for the forward slip on the exit side. In case regularization is applied, this equation can be rewritten as:

$$
q=\mu p \cdot \frac{v_{\mathrm{s}}}{\sqrt{v_{\mathrm{s}}^{2}+K_{\mathrm{reg}}^{2} \cdot V_{\text {roll }}^{2}}}
$$

Note that here, $V_{\text {roll }}$, the work roll velocity, has been introduced to make the regularization coefficient (now $K_{\text {reg }}$ ) non-dimensional. The slip velocity $v_{\mathrm{s}}$ can be expressed using the volume conservation principle. Neglecting elastic compressibility:

$$
v_{\mathrm{s}}=\left(\frac{t_{\mathrm{n}}}{t_{\mathrm{x}}}-1\right) V_{\text {roll }}
$$

$t_{\mathrm{n}}$ and $t_{\mathrm{x}}$ are the thickness of the strip at the neutral point and at point $x$, respectively.

(b) In the elastic zones at entry and exit of the roll bite, where slip necessarily takes place, the elastic constitutive equations and the equilibrium equation are reprocessed according to Le and Sutcliffe [17]:

$$
\frac{\mathrm{d} p}{\mathrm{~d} x} \cong-\frac{E_{s}^{*}}{t} \frac{\mathrm{d} t}{\mathrm{~d} x}+\frac{v_{\mathrm{s}}}{1-v_{\mathrm{s}}} \frac{2 q}{t}
$$


(c) In the contained plastic zone (CPZ), the pressure gradient and shear stress for roll and strip are calculated by imposing the no-slip condition, giving, instead of Equations (5) and (8):

$$
\begin{gathered}
\frac{\mathrm{d} p}{\mathrm{~d} x}=-\frac{C_{1} E_{s}^{*}}{t} \frac{\mathrm{d} t}{\mathrm{~d} x}+C_{1} \frac{1-2 v_{s}}{1-v_{s}} \frac{\mathrm{d} Y_{s}}{\mathrm{~d} x} \\
q=\frac{t}{2}\left[C_{1} \frac{\left(1-2 v_{\mathrm{s}}\right)}{\left(1-v_{\mathrm{s}}\right)}-1\right] \frac{\mathrm{d} Y_{\mathrm{s}}}{\mathrm{d} x}-Y_{s} \frac{\mathrm{d} t}{\mathrm{~d} x}-\frac{C_{1} E_{s}^{*}}{2} \frac{\mathrm{d} t}{\mathrm{~d} x} \\
C_{1}=\left[\frac{2-4 v_{s}}{1-v_{s}}-\frac{\left(1-2 v_{\mathrm{R}}\right)}{\left(1-v_{\mathrm{R}}\right)} \frac{E_{\mathrm{s}}^{*}}{E_{\mathrm{R}}^{*}}\right]^{-1}
\end{gathered}
$$

In the case of the problems addressed in this paper, both rolls and strip are made of steel, i.e., $v_{\mathrm{s}}=v_{\mathrm{R}}$ and $E_{\mathrm{s}}{ }^{*}=E_{\mathrm{R}}{ }^{*}$, so that $C_{1}=(1-v) /(1-2 v) \approx 1.8$ and Equations $(11,12)$ are simplified as:

$$
\begin{aligned}
& \frac{\mathrm{d} p}{\mathrm{~d} x}=-\frac{C_{1} E_{\mathrm{s}}^{*}}{t} \frac{\mathrm{d} t}{\mathrm{~d} x}+\frac{\mathrm{d} Y_{\mathrm{s}}}{\mathrm{d} x} \\
& q=-\left(Y_{\mathrm{s}}+\frac{C_{1} E_{\mathrm{s}}^{*}}{2}\right) \frac{\mathrm{d} t}{\mathrm{~d} x}
\end{aligned}
$$

Finally, $Y_{\mathrm{s}}$ is negligible $(\approx 0.3 \%)$ compared with the other term in Equation $(15)$, hence:

$$
q=-\left(\frac{C_{1} E_{\mathrm{s}}^{*}}{2}\right) \frac{\mathrm{d} t}{\mathrm{~d} x}
$$

This no-slip zone starts where $q(x)$ given by Equation (15b) first crosses the curve $q(x)$ for slipping condition Equations (6-9) and ends at the second intersection point. This procedure has been developed to prevent the local thickness of the strip from re-increasing inside the roll bite due to too high roll deformation.

All the equations are integrated by a Runge-Kutta method of order 4 (RK4), using typically 3000 slabs (space integration steps) for each zone.

\subsubsection{Work Roll Deformation Equations}

The work roll deformation equations applied in this work were developed by Meindl [18] and further applied for temper rolling model by Krimpelstätter [14].

A sufficient approximation for the cases dealt with here consists in taking into account radial displacement under the effect of a radial loading (Figure 5), although all four terms can be addressed, orthoradial as well as radial in terms of stress as well as displacement. Krimpelstätter [14] claims that orthoradial terms are necessary for very small reduction (temper-rolling). 

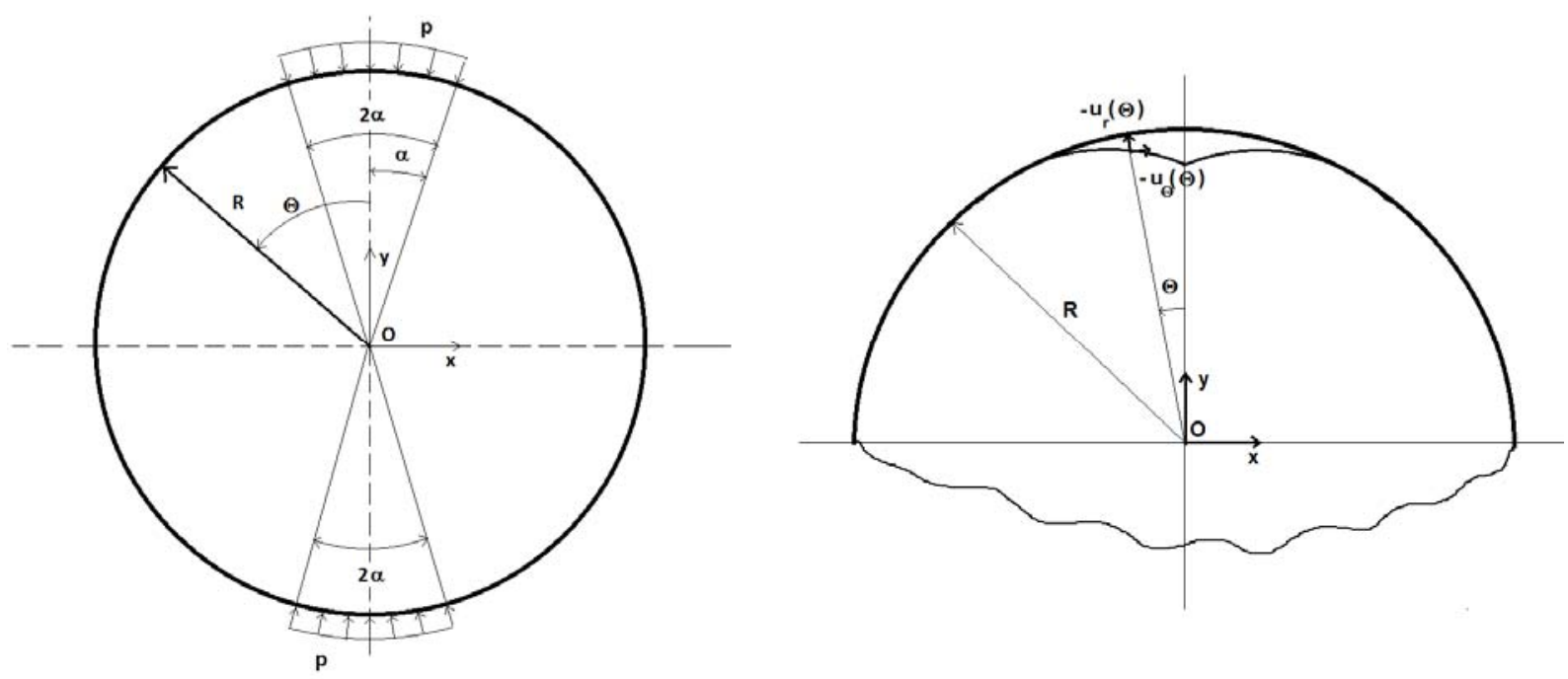

Figure 5. Principle and symbols for the influence functions method [14].

For a uniform distribution of compressive stress of small angular extension $\alpha$, the radial work roll surface displacement is given analytically for a generalized plane strain state by: for $\frac{-\pi}{2}<\Theta<-\alpha$ (i.e., outside the load area)

$$
\begin{aligned}
u_{r}(\Theta)=\frac{p R}{E \pi}( & \left.1-v^{2}\right)\left[\frac{\pi}{2}\left(\frac{v}{1-v}-1\right) \cos (\Theta+\alpha)+\sin (\Theta+\alpha) \ln \left(\tan ^{2} \frac{\Theta+\alpha}{2}\right)\right] \\
& -\frac{p R}{E \pi}\left(1-v^{2}\right)\left[\frac{\pi}{2}\left(\frac{v}{1-v}-1\right) \cos (\Theta-\alpha)\right. \\
& \left.+\sin (\Theta-\alpha) \ln \left(\tan ^{2} \frac{\Theta-\alpha}{2}\right)\right]-\frac{4 p \alpha v^{2} R}{\pi E}
\end{aligned}
$$

for $-\alpha<\Theta<\alpha$ :

$$
\begin{aligned}
u_{r}(\Theta)=\frac{p R}{2 E}\left(1-v^{2}\right)\left(\frac{v}{1-v}-1\right)[2-\cos (\Theta-\alpha)-\cos (\Theta+\alpha)] \\
+\frac{p R}{E \pi}\left(1-v^{2}\right)\left[\sin (\Theta+\alpha) \ln \left(\tan ^{2} \frac{\Theta+\alpha}{2}\right)-\sin (\Theta-\alpha) \ln \left(\tan ^{2} \frac{\Theta-\alpha}{2}\right)\right] \\
-\frac{4 p \alpha v^{2} R}{\pi E}
\end{aligned}
$$

for $\alpha<\Theta<\frac{\pi}{2}$

$$
\begin{gathered}
u_{r}(\Theta)=\frac{p R}{E \pi}\left(1-v^{2}\right)\left[-\frac{\pi}{2}\left(\frac{v}{1-v}-1\right) \cos (\Theta+\alpha)+\sin (\Theta+\alpha) \ln \left(\tan ^{2} \frac{\Theta+\alpha}{2}\right)\right] \\
-\frac{p R}{E \pi}\left(1-v^{2}\right)\left[-\frac{\pi}{2}\left(\frac{v}{1-v}-1\right) \cos (\Theta-\alpha)\right. \\
\left.+\sin (\Theta-\alpha) \ln \left(\tan ^{2} \frac{\Theta-\alpha}{2}\right)\right]-\frac{4 p \alpha v^{2} R}{\pi E}
\end{gathered}
$$

The deformation of the roll for any general distribution of pressure can then be calculated through the superposition principle.

Note that these influence functions are developed for a diametrically symmetric loading (Figure 5). This is not exactly the case of strip rolling, since the work-roll/back-up roll contact is shorter and therefore under higher contact stress than the strip/work roll contact. However, the contact length (a few 
$\mathrm{mm}$ ) is much smaller than the roll diameter (typically 400 to $600 \mathrm{~mm}$ in cold rolling). Hence, thanks to Saint-Venant's principle, only the resultant load at work roll/back-up roll contact needs to be exact, not its distribution. The precision of the solution is not impaired.

Displacement is calculated on a roll fraction roughly twice as long as the arc of contact, divided into 200 intervals so that $\alpha=2.7 \times 10^{-4}$ radian.

\subsubsection{Numerical Implementation}

Figure 6 shows the flow chart of the global numerical scheme. Some points are detailed hereafter, a more complete explanation can be found in Le and Sutcliffe [17]. The model is iterative with two main loops: the global loop and the Neutral Point loop.

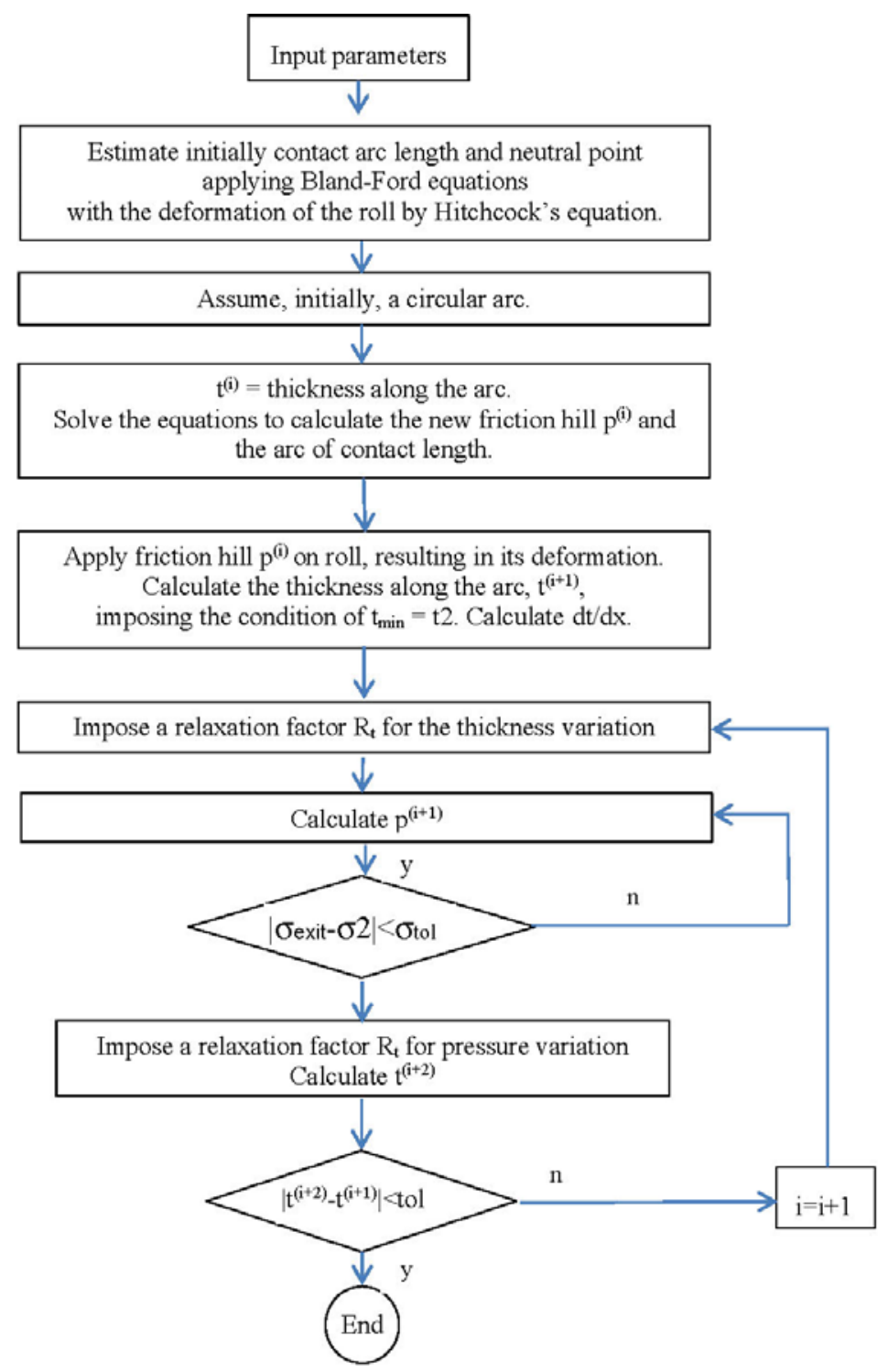

Figure 6. Global flow chart of the Slab Method model.

a-In the global cycle, the thickness distribution and the pressure are calculated. The process is considered converged when: 


$$
\max |t(i+2)-t(i+1)|<t o l
$$

where tolerance $t o l=0.01 t_{1}$ (entry strip thickness) typically. A relaxation factor $R_{t}$ is used for both thickness and pressure profiles:

$$
\text { updated pressure }=R_{\mathrm{t}} \times \text { current pressure }+\left(1-R_{\mathrm{t}}\right) \times \text { previous pressure }
$$

In the applications shown here, $R_{\mathrm{t}}$ ranges from 0.1 to 0.5 ( 0.1 for the most severe cases). An analogous expression is applied for the thickness profile.

b-In the neutral point cycle, the neutral point is calculated so as to satisfy:

$$
\sigma\left(x_{\mathrm{e}}\right)=\sigma_{2}
$$

$\sigma_{2}$ is the (given) front tension stress, $x_{\mathrm{e}}$ is the contact exit abscissa (Figure 4). Starting the stress integration from $\sigma=\sigma_{1}$ (the back tension stress) at $x=x_{\mathrm{a}}, \sigma\left(x_{\mathrm{e}}\right)$ changes with the position $x_{\mathrm{N}}$ of the neutral point where the sign of $q$ is changed in Equation (7). Using a secant method, the neutral point is found in general in three or four steps. For more stringent situations, though, the tolerance for the value of the resulting exit tension stress must be chosen larger in the initial iterations.

\subsection{FEM-Based Model}

The model used is based on two items:

- A 3D implicit FEM software called Lam3, fully described by Hacquin [19,20]. It is used here in its steady state option based on streamlines. The integration of the elastic-plastic constitutive model uses the radial return technique; the compatibility with steady state modeling and the streamline method is ensured through the ELDTH formulation (Eulerian-Lagrangian with Heterogeneous Time step). The software uses 8-node hexahedra with reduced pressure integration. Steady state allows adapted refinement in critical locations (bite entry and exit). Thermo-mechanical coupling is not activated here.

- A 3D semi-analytical elastic roll deformation model called Tec3, fully described in Hacquin et al. [21]. It combines roll bending based on Timoshenko's beam model, roll flattening based on Boussinesq equations for a semi-infinite solid arbitrarily loaded on its surface, Hertz contact theory for the work roll/back-up roll contact. End effects for the complex geometry and boundary conditions of the roll barrel edge have been corrected by analytical expressions derived from extensive FEM comparisons. All equations are discretized by a 3D influence function method. Due to the unknown work roll/back-up roll contact areas, the resulting equations are non-linear and are solved using a Newton-Raphson scheme.

Coupling between the two models is performed by a fixed-point technique with relaxation.

Here, the combined model is used in 2D plane strain, obtained by (1) embedding one layer of elements between two symmetry planes parallel to the rolling direction; and (2) imposing an infinite stiffness in the roll deformation model for bending terms only. In this way, a solution equivalent to the 2D model of Section 3.1 is obtained. 


\section{Influence of the Regularization Parameter on Rolling Process Mechanics}

The parameters used in this work are shown in Table 1, those of the friction models in Table 2 .

Table 1. Description of the rolling pass investigated in this paper.

\begin{tabular}{cc}
\hline Variable & Value \\
\hline Inlet/exit thickness, $t_{1} / t_{2}$ & $0.355 \mathrm{~mm} / 0.252 \mathrm{~mm}$ \\
Work roll diameter & $555 \mathrm{~mm}$ \\
Work roll velocity & $20.482 \mathrm{~m} \cdot \mathrm{s}^{-1}$ \\
Back/front tension stress, $\sigma_{1} / \sigma_{2}$ & $170 \mathrm{MPa} / 100 \mathrm{MPa}$ \\
Young's modulus (roll and strip) & $210 \mathrm{GPa}$ \\
Poisson's ratio (roll and strip) & 0.3 \\
Flow curve & $Y=(470.5+175.4 \varepsilon) \times\left(1-0.45 \mathrm{e}^{-8.9 \varepsilon}\right)-25(\mathrm{MPa})$ \\
Accumulated strain (prior to the pass investigated) & 2.05 \\
\hline
\end{tabular}

Table 2. Non-dimensional parameters of the friction models.

\begin{tabular}{cc}
\hline$\mu$ & $0.02 ; 0.04$ \\
$K_{\text {reg }}($ Slab Method $)$ & $10^{-2} ; 3.16 \times 10^{-3} ; 10^{-3}$ \\
$K_{\text {reg }}$ (FEM) & $10^{-1} ; 10^{-2} ; 3.1610^{-3} ; 10^{-3}$ \\
\hline
\end{tabular}

Note that $K_{\text {reg }}=10^{-1}$ is not used in Section $3.2(\mathrm{SM})$ as Section 3.1 (FEM) will show this value to be too large.

\subsection{Impact of Friction Regularization: FEM}

Figure 7 pictures the evolution of the friction stress profile with $K_{\text {reg }}$ in the range of $10^{-3}-10^{-1}$ for a

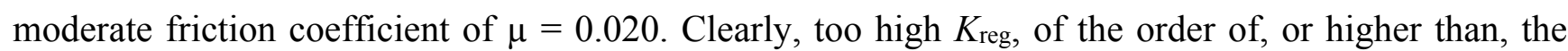
typical $v_{\mathrm{s}} / V_{\text {roll, }}$, completely changes the friction stress pattern, and therefore all the mechanics of the rolling process. The roll load $F$ is $10.2 \mathrm{MN} \cdot \mathrm{m}^{-1}$ for $K_{\text {reg }}=10^{-3}, 9.59 \mathrm{MN} \cdot \mathrm{m}^{-1}$ for $K_{\text {reg }}=10^{-2}$ and $7.47 \mathrm{MN} \cdot \mathrm{m}^{-1}$ for $K_{\mathrm{reg}}=10^{-1}$.
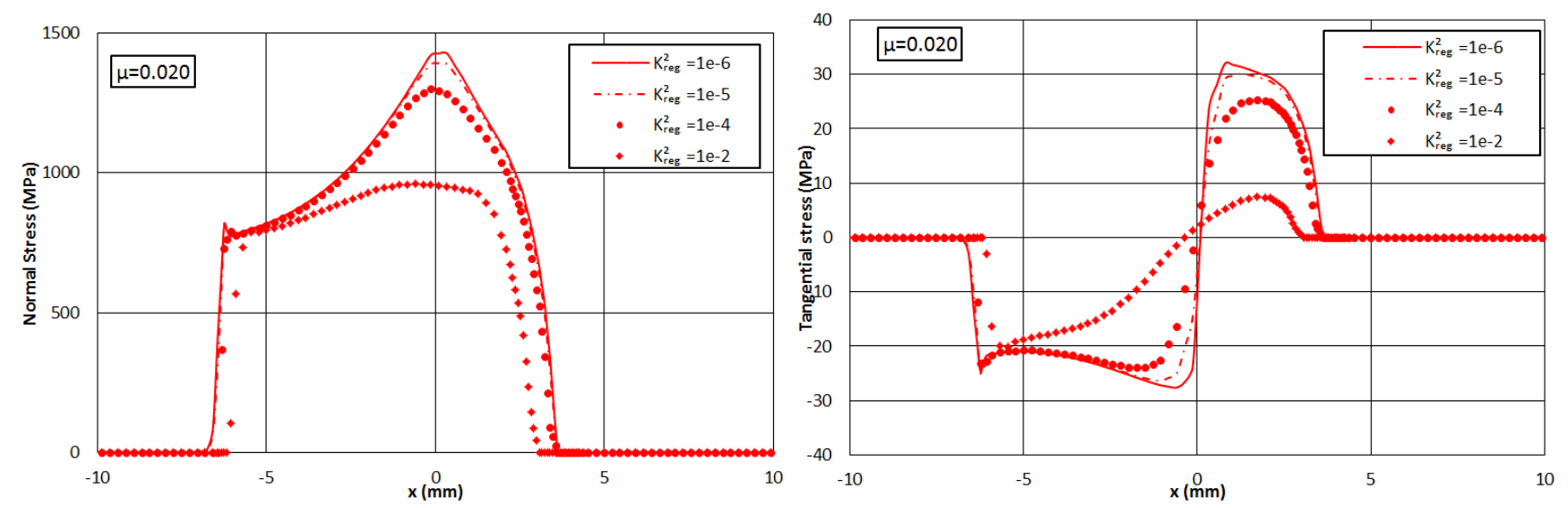

Figure 7. Impact of regularization parameter $K_{\text {reg }}$ on normal (left) and friction stress (right). Coulomb friction coefficient $\mu=0.020$. 
This emphasizes the danger of this technique if introduced without careful control with numerical reasons in mind. On the contrary, lower values respect the physics of Coulomb's friction. They have a limited, local action in the vicinity of the neutral point, relieving excessive stress there and facilitating the convergence of the roll deformation coupling. Too low values may, however, leave one with too stiff a problem, jeopardizing convergence.

In Figure 8, the inflexion in the $v_{s}(x)$ curve corresponds to roll deformation at the location of maximum normal stress; it is absent when $K_{\text {reg }}=10^{-1}$ due to a much lower normal stress.
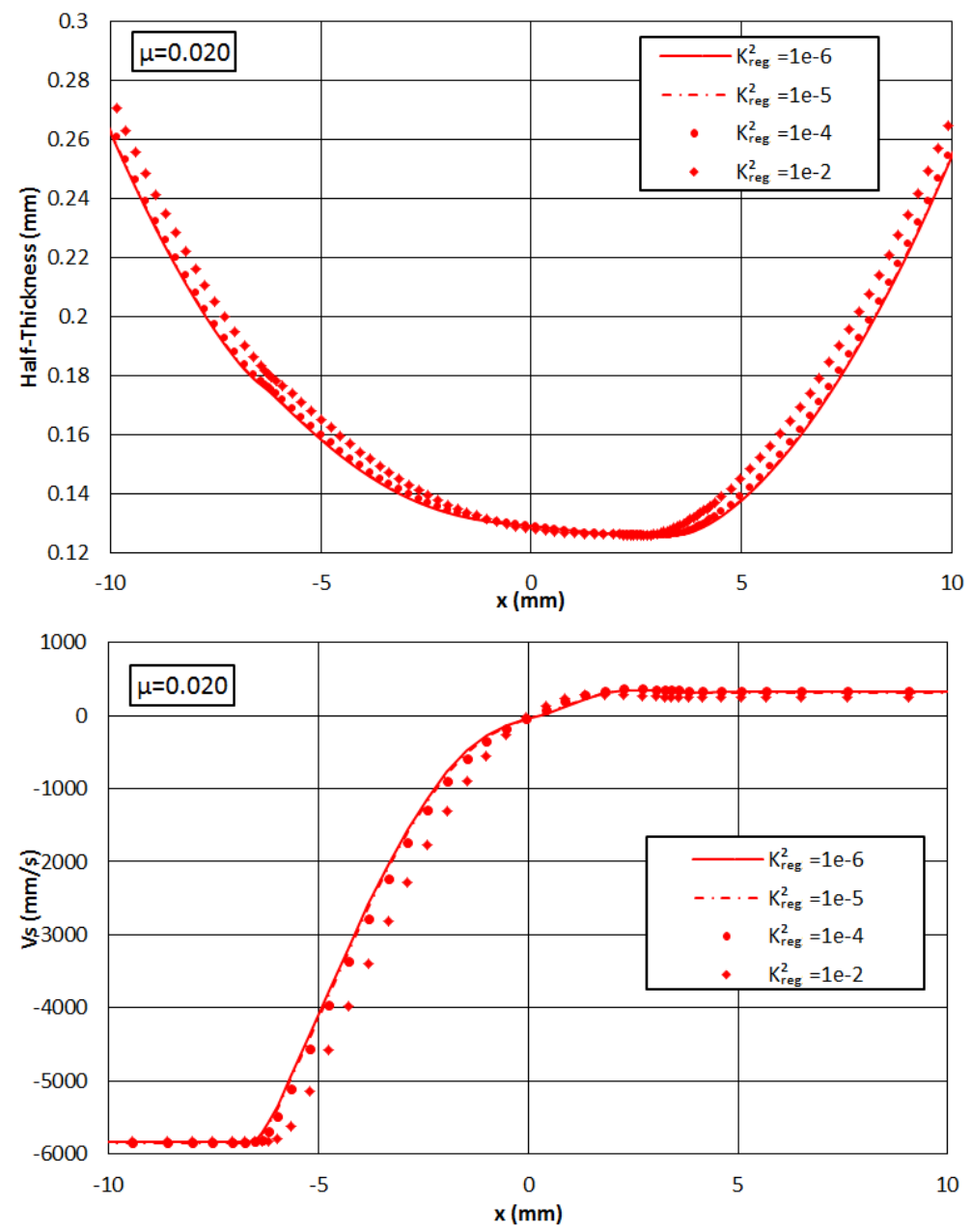

Figure 8. Impact of regularization parameter $K_{\text {reg }}$ on roll profile (top) and on sliding velocity $v_{\mathrm{s}}$ (bottom), $\mu=0.020$.

\subsection{Impact of Friction Regularization: Slab Method}

Figures 9 and 10 display the impact of regularization in the two extreme cases investigated: lowest ( $\mu=0.02)$ and highest $(\mu=0.04)$ friction. Based on the previous results, the highest value $K_{\text {reg }}=10^{-1}$ is discarded (Table 2). In all cases, "strong" regularization $\left(K_{\text {reg }}=10^{-2}\right)$ significantly changes the local friction stress in the vicinity of the neutral point, i.e., where sliding speed is small. The sliding velocity $\nu_{\mathrm{s}}$ varies from $-5120 \mathrm{~m} \cdot \mathrm{s}^{-1}\left(v_{\mathrm{s}} / V_{\text {roll }} \sim-0.25\right)$ at entry to 0 at the neutral point. For low friction (left side of the figure) where roll deformation is moderate, the impact on normal stress is visible but moderate, and the difference of deformed roll profiles (Figure 10) is very small. Note that the entry point is to be 
found at $y=0.1175 \mathrm{~mm}$. The rolling force, which is practically the integral of the vertical stress profile, varies between $10.1 \mathrm{MN} \cdot \mathrm{m}^{-1}$ for the non-regularized case and $9.68 \mathrm{MN} \cdot \mathrm{m}^{-1}$ for $K_{\text {reg }}=10^{-2}(-4 \%)$ for the low friction case $(\mu=0.020)$. For $\mu=0.04$, it increases by $6 \%$, from $29.90 \mathrm{MN} \cdot \mathrm{m}^{-1}$ without regularization to $31.6 \mathrm{MN} \cdot \mathrm{m}^{-1}$ for $K_{\mathrm{reg}}=10^{-2}$.

The high friction case $(\mu=0.04)$ calls for three comments. First, the magnitude of the normal stress, more than twice as high compared with $\mu=0.02$, illustrates the very high sensitivity of such thin strip configurations. The friction stress is therefore up to four times larger $(\mu \times 2$ and $p \times 2)$, and the shape of the stress profiles is distorted by the roll-deformed profile. Second, the impact of regularization is the same as in the previous case. In the central, contained plasticity zone where the roll profile is flat, the friction stress drops considerably due to the no-slip condition Equation (2b). This effect is also well captured by the regularized friction model. Third, comparing results for non-regularized and "little regularized" $\left(K_{\text {reg }}=10^{-3}\right)$ models, it is found that the normal and tangential stresses with regularized friction are larger (Figure 9). This is surprising since Equation (4) suggests that friction stresses decrease by the regularization. However, it is important to note that in the Contained Plastic Region (CPZ), a change in the treatment of stress integration is introduced, replacing Equation (6) by Equations (14) and (8) by Equation (15b) — see Section 3: as shown by the roll profiles, this has an effect on all aspects of the contact mechanics.

\section{Discussions}

\subsection{Importance of Friction Regularization and Choice of $K_{\text {reg }}$}

The introduction of friction regularization, in the SM context, just aims at improving convergence in critical cases. Critical cases are those where a significant "neutral zone" under (quasi-) sticking condition develops, leading to the coexistence of sticking and slipping zones. This happens both for very low reduction, the so-called "temper rolling" of steels, and for heavily loaded case, i.e., high reduction of thin strips of hard metal.
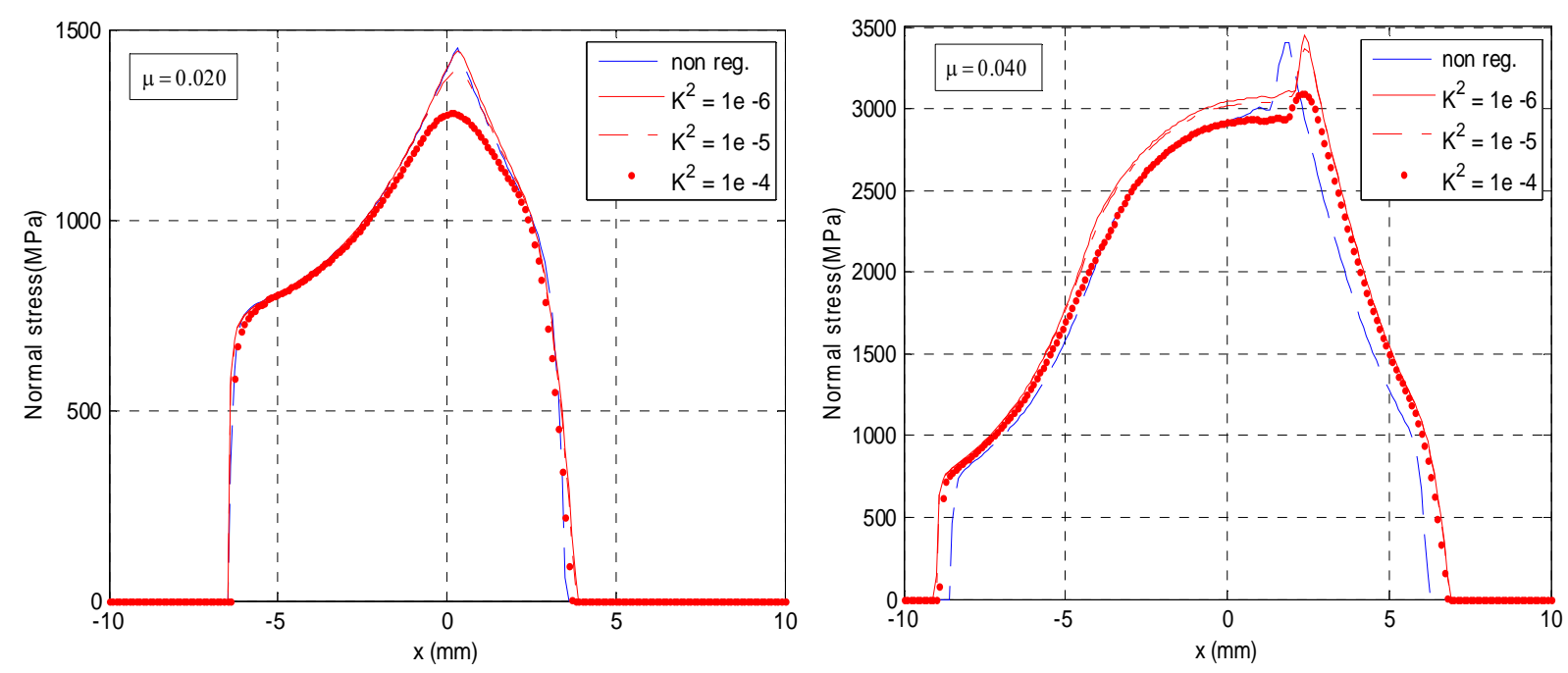

Figure 9. Cont. 

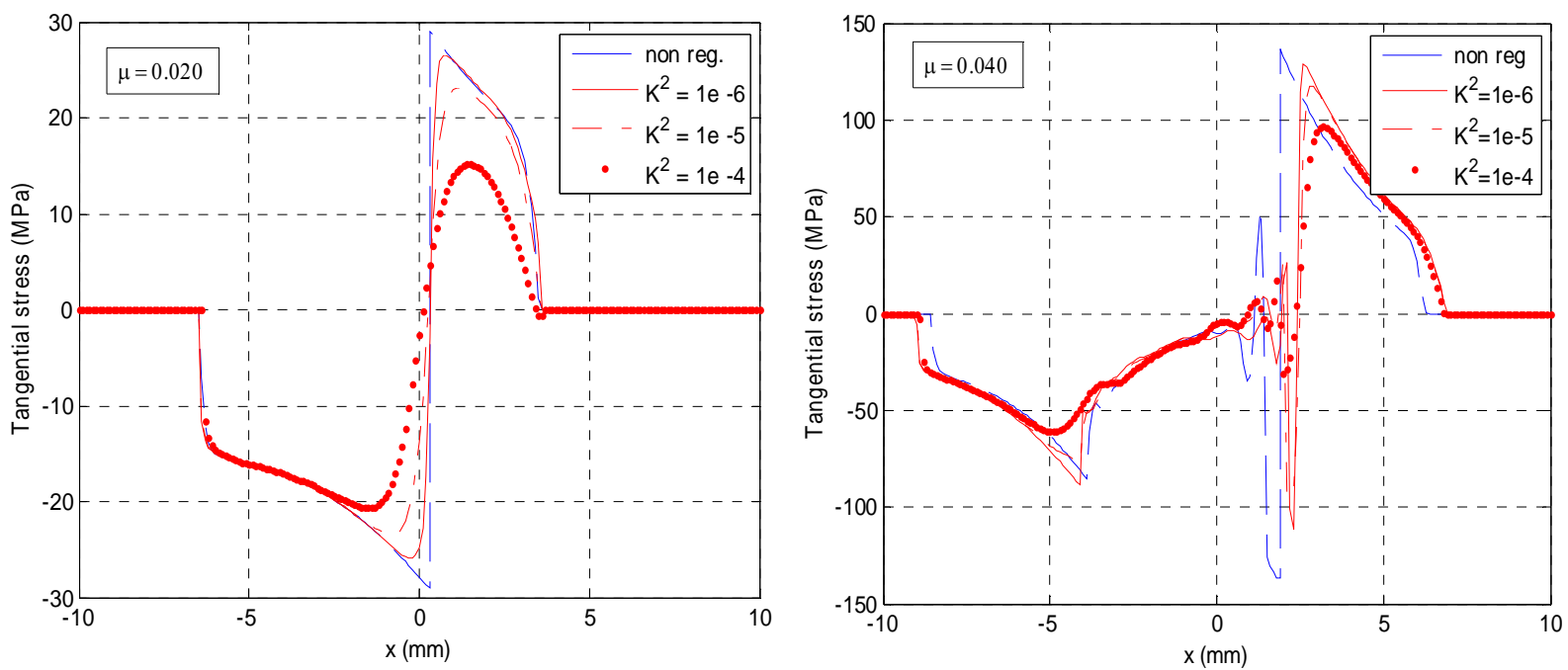

Figure 9. Impact of friction regularization on mechanical variables in thin strip cold rolling, Slab Method. (Left) $\mu=0.020$; (right) $\mu=0.040$. From (top) to (bottom), profiles of the normal stress, of the friction stress.
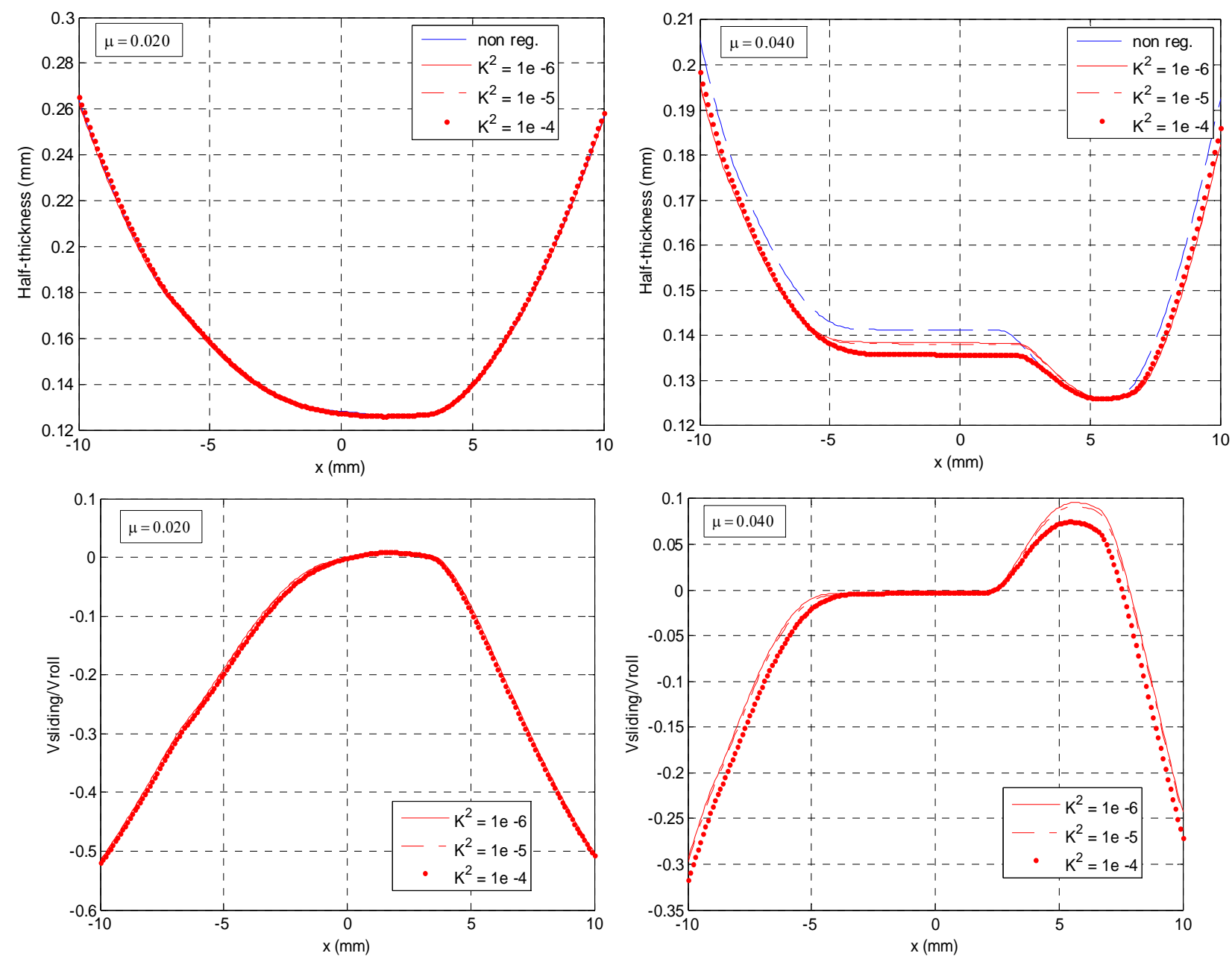

Figure 10. Impact of friction regularization on mechanical variables in thin strip cold rolling, Slab Method. (Left) $\mu=0.020$; (right) $\mu=0.040$. From (top) to (bottom), profiles of the deformed roll and of the sliding velocity. 
Both are characterized by large roll elastic deformation with a central flat zone around the neutral point, rather similar to the shape of the solid surfaces in Elasto-Hydrodynamic Lubrication (EHL) - see Fleck and Johnson [15]. This similarity characterizes problems with heavy loadings where the solution is dominated by the elastic sub-problem rather than the flow of the fluid or metal in between: by virtue of their very thinness, a thin oil film or a thin metal strip are stiffer than the roller itself.

For other types of rolling operations, regularization is not necessary in the SM. On the contrary, the FEM needs regularization because the derivative of the sliding condition $\tau\left(v_{\mathrm{s}}\right)$ has to be computed for the stiffness matrix and is singular at $v_{\mathrm{s}}=0$. Regularization by smoothing velocity dependence is introduced most of the time, although "elastic" regularization has also been proposed [22]: it consists in adding a small capacity for reversible tangential movement before gross sliding.

Coming back to velocity regularization, as shown above, too small $K$ may lead to convergence problems in the FEM due to quasi-singular stiffness matrix, or to difficult-to-handle solutions in the SM (increase of the thickness inside the bite). But too large $K$ may completely alter the physical content of the friction law, introducing an artificial velocity dependency, and change substantially the mechanical description of the rolling operation. Table 3 summarizes the impact of $K_{\text {reg }}$ on the roll load and the neutral zone length. For the rolling operation investigated, the difference between SM and FEM is not more than $1 \%$. It is clear again that $K_{\text {reg }}=10^{-1}$ is inadequate; this is why the study has been restricted to $K_{\text {reg }} \leq 10^{-2}$ for SM. Even for $K_{\text {reg }}=10^{-2}$, some influence shows, $5 \%$ for these particular rolling conditions.

Table 3. Variations of global variables (roll load, length of neutral zone) on $K_{\text {reg. }}$.

\begin{tabular}{ccccc}
\hline $\boldsymbol{K}_{\text {reg }}$ & $\begin{array}{c}\text { Force }(\mathbf{M N} / \mathbf{m}), \mathbf{F E M}, \\
\boldsymbol{\mu}=\mathbf{0 . 0 2}\end{array}$ & $\begin{array}{c}\text { Force }(\mathbf{M N} / \mathbf{m}), \\
\mathbf{S M}, \boldsymbol{\mu}=\mathbf{0 . 0 2}\end{array}$ & $\begin{array}{c}\text { Force }(\mathbf{M N} / \mathbf{m}), \\
\mathbf{S M}, \boldsymbol{\mu}=\mathbf{0 . 0 4}\end{array}$ & $\begin{array}{c}\mathbf{L}_{\text {stick }}(\mathbf{m m}) \mathbf{S M}, \\
\boldsymbol{\mu}=\mathbf{0 . 0 4}\end{array}$ \\
\hline $10^{-1}$ & $7.47 \mathrm{MN} / \mathrm{m}$ & - & - & - \\
$10^{-2}$ & $9.59 \mathrm{MN} / \mathrm{m}$ & $9.68 \mathrm{MN} / \mathrm{m}$ & $31.6 \mathrm{MN} / \mathrm{m}$ & $5.5 \mathrm{~mm}$ \\
$3.1610^{-3}$ & $10.1 \mathrm{MN} / \mathrm{m}$ & $10.1 \mathrm{MN} / \mathrm{m}$ & $33.1 \mathrm{MN} / \mathrm{m}$ & $6.2 \mathrm{~mm}$ \\
$10^{-3}$ & $10.2 \mathrm{MN} / \mathrm{m}$ & $10.1 \mathrm{MN} / \mathrm{m}$ & $33.4 \mathrm{MN} / \mathrm{m}$ & $6.4 \mathrm{~mm}$ \\
Non-regularized & - & $10.1 \mathrm{MN} / \mathrm{m}$ & $29.9 \mathrm{MN} / \mathrm{m}$ & $5.5 \mathrm{~mm}$ \\
\hline
\end{tabular}

A more comprehensive study would be needed, but as a rule of thumb, taking $K_{\text {reg }}=10^{-2}$ times the reduction seems a good compromise for rolling. This means $K_{\text {reg }}=10^{-3}$ for $10 \%$ reduction and $K_{\text {reg }}=10^{-4}$ for $1 \%$ reduction in temper rolling where expected sliding velocities are very low.

It must be emphasized that non-dimensionalizing $K$ into $K_{\text {reg }}$ is important: it is quite difficult to understand what one is doing and to control its effect otherwise. This is the same as for friction for which, whatever the friction model, non-dimensional coefficients should always be used, such as Coulomb's friction coefficient or the friction factor.

\subsection{Generality of the Approach}

Although different forms may be proposed for velocity regularization of friction (see $\mathrm{Li}$ and Kobayashi [23] for an alternative), this technique can be used universally, wherever it may be useful and under conditions such that it does not alter the solution of the problem (see above). This is different from the models (SM and FEM), which have been used here to address the regularization issue. The SM is valid for most cases of cold strip rolling, wherever the impact of the neglected shear strains and stresses 
is not too strong. This means very low bite angle in rolling. The validity can be extended using the Orowan enhancement technique [9,12]. However, 2D SM of course cannot deal with intrinsically 3D problems such as strip profile and flatness or strip lateral widening or shrinking ("spread"). The FEM on the contrary is universally valid; its limitation to 2D here is purely a restriction to the scope of the paper. The roll deformation model by the Influence Function Method (IFM), in 2D or 3D, has a great precision at low cost; it belongs to a very general solution technique in elasticity theory. The one used here is limited to 4-high or 6-high mills, when all roll centerlines are in a same vertical plane; however, similar techniques are available for e.g., cluster mills such as Sendzimir mills [24].

\subsection{Coupling Regularization with the Static/Dynamic Friction Concept}

Finally, this paper compares two ways of dealing with the spatial coexistence of sticking and sliding zones, a variant of the static/dynamic transition, in the space rather than time domain due to the steady state character of the mechanism investigated, the strip-roll contact in strip rolling processes. The regularization technique could offer a way to introduce a difference between static friction ( $\left.\mu_{\text {stat}}\right)$ and dynamic friction $\left(\mu_{\mathrm{dyn}}\right)$. The presently chosen regularization function in Equation (4b) varies monotonically between 0 for $v_{\mathrm{s}}=0$ and 1 when $v_{\mathrm{s}}$ tends to infinity, but it is easy to provide a function that starts from 0 , reaches asymptotically 1 but has a peak larger than 1 in the vicinity of $v_{\mathrm{s}}=0$, e.g.,

$$
q=\mu_{d y n} p \cdot \frac{v_{s}^{2}+a \cdot V_{\text {roll }} \cdot v_{s}}{v_{s}^{2}+b^{2} \cdot V_{\text {roll }}^{2}}
$$

Its slope at $v_{\mathrm{s}}=0$ is $a / b^{2}$, the peak is at $v_{\mathrm{s}}=\frac{b^{2}}{a} \cdot\left(1+\sqrt{1+\frac{a^{2}}{b^{2}}}\right)$ and:

$$
\frac{\mu_{\mathrm{stat}}}{\mu_{\mathrm{dyn}}}=1+\frac{1}{2} \cdot \frac{\sqrt{1+a^{2} / b^{2}}}{1+b^{2} / a^{2}\left(1+\sqrt{1+a^{2} / b^{2}}\right)}
$$

The two parameters allow selecting separately $\mu_{\text {stat }} / \mu_{\text {dyn }}$ and the initial slope or the position of the peak. Any more convenient function may of course be proposed. The impact of such a variant could be the subject of future work.

\section{Conclusions}

Two ways of dealing with the slip/no-slip transition within the roll bite in thin strip rolling have been presented. In the no-slip, contained plasticity zone, the $|q|<\mu p$ condition can be enforced by comparing the on-going friction stress with the one deduced from the no-slip condition added to the $\mathrm{d} t / \mathrm{d} x=0$ condition. As a result, $q$ drops in the static friction zones. The same effects can be reproduced in a simpler way by introducing regularization. Although minor differences are found due to the algorithmic complexity of the first method, the shapes of the friction stress profile and the normal stress profile coincide to less than $1 \%$ provided the choice of the regularization parameters is made with care. It must be large enough not to raise convergence difficulties, small enough to stick to the initial problem, since too large values are equivalent to a decrease of friction coefficient. 


\section{Acknowledgments}

The authors wish to thank Coordenação de Aperfeiçoamento de Pessoal de Nível Superior (CAPES) and Centro Federal de Educação Tecnológica de Minas Gerais for providing Yukio Shigaki international mobility grant for his stay at CEMEF.

\section{Author Contributions}

Yukio Shigaki has developed the slab model NonCirc and run the application to the test cases; Rebecca Nakhoul has run the test cases using the FEM software LAM3; Pierre Montmitonnet has supervised this work.

\section{Conflicts of Interest}

The authors declare no conflict of interest.

\section{References}

1. Roberts, W.L. Flat Processing of Steel; Marcel Dekker: New York, NY, USA, 1988.

2. Johnson, K.L. Contact Mechanics, 1st ed.; Cambridge University Press: Cambridge, UK, 1985.

3. Hitchcock, J.H. Roll neck bearings. Report ASME Res. Comm. 1935.

4. Bland, D.R.; Ford, H. The calculation of roll force and torque in cold strip rolling with tensions. Proc. Inst. Mech. Eng. 1948, 159, 144-153.

5. Montmitonnet, P.; Wey, E.; Delamare, F.; Chenot, J.-L.; Fromholz, C.; de Vathaire, M. A mechanical model of cold rolling. Influence of the friction law on roll flattening calculated by a Finite Element Method. In Proceedings of the 4th International Steel Rolling Conference, Deauville, France, 1-3 June, 1987.

6. Jortner, D.; Osterle, J.F.; Zorowski, C.F. An analysis of cold strip rolling. Int. J. Mech. Sci. 1960, 2, 179-194.

7. Atreya, A.; Lenard, J.G. A study of cold strip rolling. J. Eng. Mater. Technol. (Trans. ASME) 1979, $101,129-134$.

8. Kim, T.H.; Lee, W.H.; Hwang, S.M. An integrated FE process model for the prediction of strip profile in flat rolling. ISIJ Int. 2003, 43, 1947-1956.

9. Orowan, E. The calculation of roll pressure in hot and cold flat rolling. Proc. Inst. Mech. Eng. 1943, $150,140-167$.

10. Grimble, M.J.; Fuller, M.A.; Bryant, G.F. A non-circular arc force model for cold rolling. Int. J. Numer. Methods Eng. 1978, 12, 643-663.

11. Gratacos, P.; Montmitonnet, P.; Fromholz, C.; Chenot, J.-L. A plane strain elastoplastic finite element model for cold rolling of thin strip. Int. J. Mech. Sci. 1992, 34, 195-210.

12. Matsumoto, H. Elastic-Plastic Theory of Cold and Temper Rolling. In Proceedings of the 8th International Conference on Technology of Plasticity, Verona, Italy, 9-13 October, 2005.

13. Legrand, N.; Ngo, T.; Suzuki, Y.; Takahama, Y.; Dbouk, T.; Montmitonnet, P.; Matsumoto, H. Advanced Roll Bite Models for Cold and Temper Rolling Processes. In Proceedings of the Rolling 2013 Conference, Venice, Italy, 10-12 June 2013. 
14. Krimpelstätter, K. Non circular arc temper rolling model considering radial and circumferential displacements. Ph.D. Thesis, Linz University, Linz, Austria, 2005 (In German).

15. Fleck, N.A.; Johnson, K.L. Towards a new theory of cold rolling thin foil. Int. J. Mech. Sci. 1987, 29, 507-524.

16. Sutcliffe, M.P.F.; Montmitonnet, P. Numerical modelling of lubricated foil rolling. Rev. Met. SGM 2001, 98, 435-442.

17. Le, H.R.; Sutcliffe, M.P.F. A robust model for rolling of thin strip and foil. Int. J. Mech. Sci. 2001, 43, 1405-1419.

18. Meindl, W. Roll flattening with consideration of shear contact stress. Ph.D. Thesis, Linz University, Linz, Austria, 2001 (In German).

19. Hacquin, A. Modélisation Thermomécanique Tridimensionnelle du Laminage: Couplage Bande-Cylindres (3D Thermomechanical Modelling of Rolling Processes: Coupling Strip and Rolls). Ph.D. Dissertation, MINES ParisTech, Paris, France, 1996 (In French).

20. Hacquin, A.; Montmitonnet, P.; Guillerault, J.P. A steady state thermo-elastoviscoplastic finite element model of rolling with coupled thermo-elastic roll deformation. J. Mat. Proc. Tech. 1996, 60, 109-116.

21. Hacquin, A.; Montmitonnet, P.; Guillerault, J.P. A 3D semi-analytical model of rolling stand deformation with finite element validation. Eur. J. Mech. A (Solids) 1998, 17, 79-106.

22. Van der Lugt, J. A FEM for the Simulation of Thermomechanical Contact Problems in Forming Processes. Ph.D. Dissertation, Twente University, The Netherlands, 1988.

23. Li, G.J.; Kobayashi, S. Rigid plastic finite element analysis of plane strain rolling. Trans. ASME J. Eng. Mat. Technol. 1982, 104, 55-64.

24. Ogawa, S.; Hamauzu, S.; Matsumoto, H.; Kawanami, T. Prediction of flatness of fine gauge strip rolled by 12-high Cluster Mill. ISIJ Int. 1991, 31, 599-606.

(C) 2015 by the authors; licensee MDPI, Basel, Switzerland. This article is an open access article distributed under the terms and conditions of the Creative Commons Attribution license (http://creativecommons.org/licenses/by/4.0/). 